\title{
The formation mechanism of reverted austenite in Mn- based maraging steels
}

\author{
Feng Qian ${ }^{1, *}$ (1) and W. Mark Rainforth ${ }^{1}$ (I) \\ ${ }^{1}$ Department of Materials Science and Engineering, University of Sheffield, Sheffield S1 3JD, UK
}

Received: 30 October 2018

Accepted: 2 January 2019

Published online:

8 January 2019

(C) The Author(s) 2019

\begin{abstract}
Based on the microstructural evolution in Mn-based maraging steels aged at $460-540{ }^{\circ} \mathrm{C}$, the formation mechanism of reverted austenite is proposed. Reverted austenite formed at grain boundaries at the onset of aging. During further aging, the accumulated Mn enrichment at newly formed $\alpha^{\prime} / \gamma$ interfaces led to thin austenite layers growing into lath-like austenite grains. The lateral growth of lath-like reverted austenite was sluggish, reflecting the low diffusivity of $\mathrm{Mn}$. We show that reverted austenite formed by a shear-dominated mechanism assisted by a small amount of Mn diffusion, whereas the nucleation of reverted austenite within martensite laths was kinetically slower.
\end{abstract}

\section{Introduction}

A group of lean Mn-based maraging TRIP steels were recently designed by Raabe and co-workers for lightweight and safe automotive applications [1-3]. According to their study, these maraging TRIP steels exhibited a simultaneous increase in strength and elongation in the aged condition as a result of the combination of precipitation strengthening mechanism and TRIP effect of the retained austenite. The present authors have undertaken a further study on this Mn-based steel grade but with $\sim 1 \mathrm{wt} \% \mathrm{Al}$ addition [4, 5]. In contrast to the work by Raabe et al., our experimental evidence shows that no austenite was retained in the $12 \% \mathrm{Mn}$ alloy after water quenching from solution heat treatment (SHT); thus, the entire austenite in the aged samples was the product of austenite reversion from martensite. Reverted austenite, which is chemically and morphologically distinguished from retained austenite, generally provides greater microstructural synergy with martensite [3]. Many researchers have also shown that reverted austenite has a significant influence on the mechanical properties. Most of the studies on conventional maraging steels suggested that reverted austenite was detrimental to the strength [6-9], and some even reported poor ductility related to austenite reversion [10,11]. On the other hand, it has been found recently that reverted austenite in some maraging steels can markedly improve mechanical properties [1, 3, 5, 7, 12, 13]. Our recent work on Mn-based maraging steels [5] also reveals that the reverted austenite formed after longterm aging, which was characterized by high $\mathrm{Mn}$ concentration and fine grain size, was harder than the $\alpha^{\prime}$-martensite matrix and positively contributed to the strength. In addition, the brittle behavior observed in tensile tests was found to be associated with the Mn

Address correspondence to E-mail: feng.qian1101@gmail.com 
segregation at interfaces, while a transition to ductile behavior was associated with the formation and growth of reverted austenite.

The aim of the current work is to characterize the reverted austenite in Mn-based maraging steels in different conditions, and based on the microstructural investigation, a model for the formation mechanism of reverted austenite is proposed.

\section{Experimental}

Two Mn-based maraging steels [10\% Mn alloy: Fe$0.02 \mathrm{C}-10.0 \mathrm{Mn}-2.0 \mathrm{Ni}-1.2 \mathrm{Mo}-1.0 \mathrm{Al}-0.8 \mathrm{Ti}$ and $12 \% \mathrm{Mn}$ alloy: $\mathrm{Fe}-0.02 \mathrm{C}-11.8 \mathrm{Mn}-2.0 \mathrm{Ni}-1.2 \mathrm{Mo}-1.0 \mathrm{Al}-0.8 \mathrm{Ti}$ (in $\mathrm{wt} \%)]$ were initially homogenized under argon gas atmosphere at $1150{ }^{\circ} \mathrm{C}$ for $1 \mathrm{~h}$ followed by hot rolling through six passes, starting at $1140{ }^{\circ} \mathrm{C}$ and finishing at $850{ }^{\circ} \mathrm{C}$ (corresponding reduction ratio $85 \%$ ). Solution heat treatment was performed with argon protection at $1050{ }^{\circ} \mathrm{C}$ for $0.5 \mathrm{~h}$. The alloys were then aged at $460-540{ }^{\circ} \mathrm{C}$ for a range of times from 10 to $10080 \mathrm{~min}$. Microstructural characterization and compositional analysis were carried out on an FEI Inspect F scanning electron microscopy (SEM) and FEI Tecnai 20 transmission electron microscope (TEM) operated at $200 \mathrm{kV}$. TEM thin foils were prepared with a solution of 5\% perchloric acid, 35\% butoxyethanol and 60\% methanol solution (maintained at approximately $-40{ }^{\circ} \mathrm{C}$ by a liquid nitrogen cooling system) running through a twin-jet electropolisher operated at $\sim 40 \mathrm{~mA}$. Qualitative and quantitative analyses of phases were undertaken by Siemens D5000 diffractometer using Co $K_{\alpha}$ radiation $(\lambda=1.78897 \AA)$ on polished samples.

\section{Results and discussion}

The microstructural evolution of reverted austenite in the $12 \% \mathrm{Mn}$ alloy aged at $500{ }^{\circ} \mathrm{C}$ is shown in Fig. 1 . At the start of aging (10 $\mathrm{min})$, thin austenite layers were generated along boundaries in the martensitic structure (including prior austenite grain boundaries, martensite packet boundaries and martensite lath boundaries [14]) (Fig. 1b). During subsequent aging, reverted austenite layers formed independently within martensite laths and these austenite layers together with those at the martensite grain boundaries gradually grew thicker (Fig. 1c). After longer- term aging, these austenite layers finally grew into lath-like austenite grains and a lamellar structure of alternate austenite grains and martensite matrix was observed (Fig. 1d).

TEM investigation confirmed that only thin austenite layers with a size of tens of nanometers were formed at grain boundaries, whereas a large number of precipitates had formed in the martensitic matrix in the initial stage of austenite reversion (Fig. 2a). With the growth of austenite layers, lathlike reverted austenite became the dominant morphology (Fig. 2b-d), but the thickness of austenite islands did not exceed $180 \mathrm{~nm}$. TEM-EDS showed that apart from the slightly higher Mn concentration (12.9-16.2 at.\%) than that of the surrounding martensite matrix, the austenite layers formed in the initial aging stage were also enriched in $\mathrm{Ti}$ and $\mathrm{Mo}$ (inset of Fig. 2a). The Ti concentration of the austenite layers was 12.4-14.5 at.\%, and Mo concentration was between 10.5 and 13.6 at.\%. This high Ti concentration is unexpected as $\mathrm{Ti}$ is generally considered to raise the $A_{e}^{3}$ temperature and thus is not expected to be found in reverted austenite formed at these temperatures. However, atom probe tomography analyses on a similar Fe- 9 at.\% Mn maraging steel $\left(450{ }^{\circ} \mathrm{C}\right.$, $48 \mathrm{~h}$ ) by Raabe et al. [14] also revealed the enrichment of ferrite stabilizing elements, such as $\mathrm{Si}$, Mo and $\mathrm{Ti}$, at the grain boundaries where austenite nanolayers were formed. The grain boundary enrichment factors were reported as Mn 2.3, Ni 1.7, Mo 2.3, Ti 5.2 and Si 14. Thus, Ti and Mo have a high tendency to segregate to the interface, which explains the presence of $\mathrm{Ti}$ and $\mathrm{Mo}$ in austenite layers formed at grain boundaries. In contrast, the lath-like reverted austenite had a considerably higher Mn concentration (24-26.1 at.\%), whereas the $\mathrm{Ti}$ and Mo concentrations (Mo 2.9-7.3 at.\%, Ti 2.9-8.0 at.\%) (inset of Fig. 2d) were substantially less than the austenite that formed initially.

The volume fraction of reverted austenite formed when aging at $500{ }^{\circ} \mathrm{C}$ was measured by XRD and the results are presented in Table 1 . Aging at $500{ }^{\circ} \mathrm{C}$ led to a nearly linear increase in the volume fraction of reverted austenite as a function of time up to the maximum was reached for both alloys. In the $10 \%$ $\mathrm{Mn}$ alloy, the austenite phase fraction reached a maximum of $\sim 10 \mathrm{vol} . \%$ at $500{ }^{\circ} \mathrm{C} / 5760 \mathrm{~min}$ after which the content remained approximately constant. For the $12 \% \mathrm{Mn}$ alloy, the austenite fraction increased linearly up to $\sim 25 \mathrm{vol} . \%$ after $4320 \mathrm{~min}$ at $500{ }^{\circ} \mathrm{C}$ 

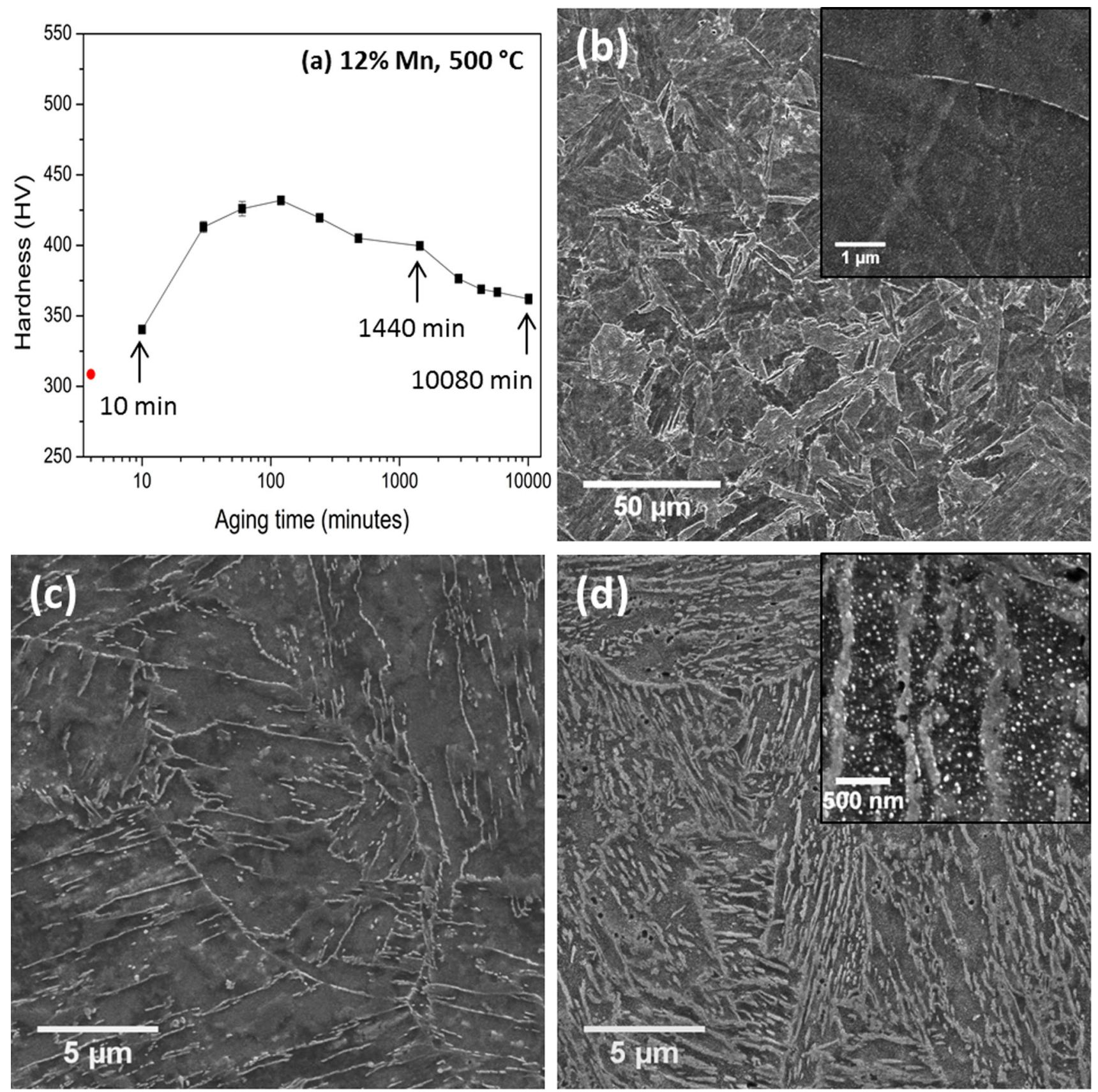

Figure 1 a Hardness evolution of $12 \% \mathrm{Mn}$ alloy aged at $500{ }^{\circ} \mathrm{C}$. SEM micrographs of reverted austenite in $12 \% \mathrm{Mn}$ alloy aged at $500{ }^{\circ} \mathrm{C}$ for b $10 \mathrm{~min}, \mathbf{c} 1440 \mathrm{~min}$ and $\mathbf{d} 10080 \mathrm{~min}$.

and then slightly decreased with aging time. This small decrease was a result of the formation of $\varepsilon^{-}$ martensitic on cooling, reported elsewhere [5]. The $\gamma \rightarrow \varepsilon$ martensitic transformation in Fe-Mn steels has been reported by other researchers [15-17]. According to Martínez et al. [16], when the Mn concentration of austenite is between 15 and $25 \mathrm{wt} \%$, up to $50 \%$ austenite transforms into $\varepsilon$-martensite during cooling.
This $\gamma \rightarrow \varepsilon$ martensitic transformation and the segregation of $\mathrm{Ti}$ at grain boundaries, which suppresses the austenite formation, are considered as the two major reasons for the lower equilibrium austenite fraction than the value predicted by MatCalc $(10 \%$ $\mathrm{Mn}$ alloy $39.4 \mathrm{vol} . \% ; 12 \% \mathrm{Mn}$ alloy $50.3 \mathrm{vol} . \%$ at $\left.500{ }^{\circ} \mathrm{C}\right)$. 

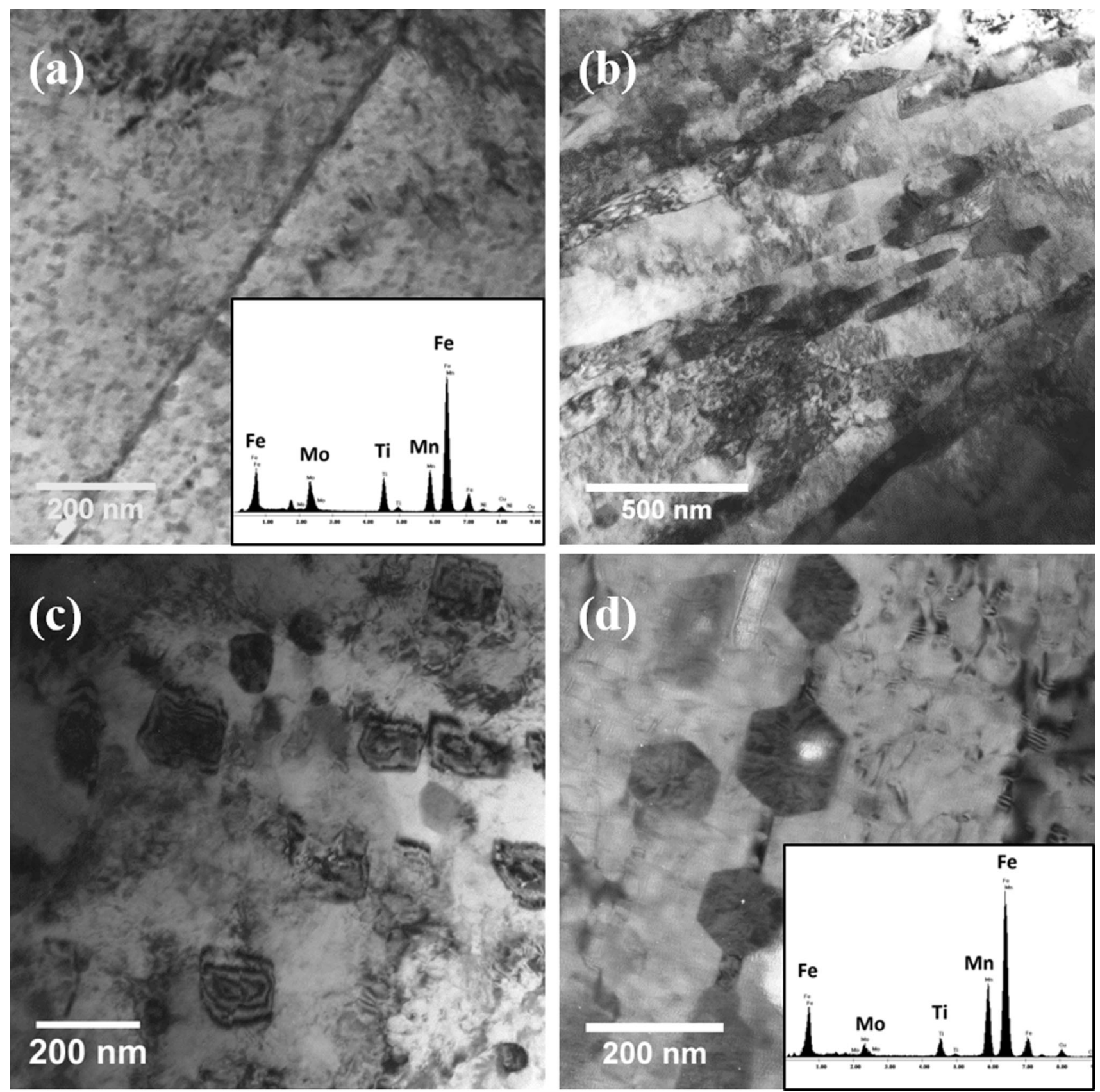

Figure 2 TEM micrographs and corresponding TEM-EDS spectra (inset) of reverted austenite in a $10 \% \mathrm{Mn}$ alloy, $500{ }^{\circ} \mathrm{C} / 1440 \mathrm{~min}$; b $12 \% \mathrm{Mn}$ alloy, $540{ }^{\circ} \mathrm{C} / 2880 \mathrm{~min}$; c and $\mathbf{d}$ are the images of reverted austenite grains from the orientation parallel to austenite laths.

The formation mechanism of lath-like austenite is a matter of debate. Many studies take the view that austenite reversion is dominated by diffusion [12, 18-20]. Schnitzer et al. [19] suggested that the growth of reverted austenite in PH 13-8 Mo maraging steels relied on the dissolution of adjacent NiAl precipitates which led to the local enrichment of $\mathrm{Ni}$. Sinha et al. [20] pointed out that, instead of precipitate dissolution, $\mathrm{Ni}$ atoms in the matrix diffuse to dislocations or other defects and generate the enrichment of austenite stabilizing elements in localized areas. Nakagawa et al. [12], Schnitizer et al. [19] and Sinha et al. [20] further reported that the activation energy for austenite formation is about $234-250 \mathrm{~kJ} / \mathrm{mol}$ which is similar to the activation energy of Ni diffusion in pure Fe (246 kJ/mol [21]). In contrast, an alternative mechanism has been proposed that the austenite reversion is shear- 
Table 1 The volume fractions (vol.\%) of reverted austenite formed when aging at $500{ }^{\circ} \mathrm{C}$

\begin{tabular}{lrr}
\hline Aging time (min) & \multicolumn{1}{c}{$10 \% \mathrm{Mn}$} & \multicolumn{1}{c}{$12 \% \mathrm{Mn}$} \\
\hline 1440 & $2.9 \pm 0.7$ & $8.5 \pm 0.7$ \\
2880 & $6.0 \pm 0.7$ & $17.1 \pm 1.8$ \\
4320 & $8.0 \pm 0.5$ & $24.8 \pm 1.3$ \\
5760 & $10.4 \pm 0.7$ & $24.6 \pm 1.5$ \\
10080 & $10.7 \pm 0.5$ & $23.1 \pm 1.4$ \\
\hline
\end{tabular}

dominated, aided by a prior or simultaneous diffusion mechanism [22-24]. This phase transformation mode is similar to the bainitic transformation, namely that a displacive transformation occurs accompanied by elemental segregation [25].

In the present study, the volume fraction of reverted austenite under a number of different conditions was studied to explore the formation mechanism of reverted austenite in Mn-based maraging steels. In order to avoid the complication and consequent error from partial transformation of austenite to $\varepsilon$-martensite upon cooling, the calculation of the activation energy for austenite formation was conducted in the period before $\varepsilon$-martensite was formed. Furthermore, the effect of precipitation in altering the matrix composition and therefore the driving force for the formation of reverted austenite is also a further complication. However, our microstructural observations revealed that the formation of reverted austenite and precipitates both initiated at the very beginning of aging, and during longer aging times, the composition of the precipitates was approximately constant [5]. The simulation study by Schnitzer et al. [19] also indicated that the dissolution of precipitates was not a factor in the initial driving force for austenite reversion. Therefore, it is assumed that the formation of precipitates and reverted austenite was independent processes in the initial aging stage. Nevertheless, these uncertainties mean that the calculation below must be still regarded as a semiquantitative description of austenite reversion.

According to Schnitzer et al. [19], if the formation of reverted austenite is governed by diffusion mechanism, its activation energy $Q$ can be calculated by:

$\ln (t)=\frac{Q}{R T}+c$ where $t$ is the time to form a certain amount of reverted austenite at a given temperature $T, R$ is the ideal gas constant and $c$ is a constant. The analyses were performed on the $10 \%$ and $12 \%$ Mn alloys by measuring the aging times required to form a defined amount of reverted austenite at $460{ }^{\circ} \mathrm{C}, 500{ }^{\circ} \mathrm{C}$ and $540{ }^{\circ} \mathrm{C}$, respectively. The chosen volume fraction of reverted austenite used in Eq. (1) was set as 4 vol.\% for the $10 \% \mathrm{Mn}$ alloy and 9 vol. $\%$ for the $12 \% \mathrm{Mn}$ alloy to avoid the formation of any $\varepsilon$-martensite. The results are presented in Fig. 3, and a linear correlation was found between $1 / T^{*} 1000$ and $\ln (t)$. Based on the slopes of the fitted lines, the activation energy for austenite reversion was estimated as $63.5 \mathrm{~kJ} / \mathrm{mol}$ for the $10 \% \mathrm{Mn}$ alloy and $85.7 \mathrm{~kJ} / \mathrm{mol}$ for the $12 \% \mathrm{Mn}$ alloy. These values are significantly lower than the activation energy for $\mathrm{Mn}$ diffusion in pure $\mathrm{Fe}$ $(219.8-261.7 \mathrm{~kJ} / \mathrm{mol}[26])$, which indicates that the formation of reverted austenite during this period was not likely to be primarily governed by the diffusion of Mn.

As noted earlier, in the early stages of aging the Mn concentration of the reverted austenite was only slightly higher than that of the adjacent martensite matrix (Fig. 2a). In addition, thermodynamic simulation indicated that a $\mathrm{Mn}$ concentration above 15.3 at.\% was sufficient to provide the chemical driving force for martensite to austenite transformation at the interface with local enrichments of $\mathrm{Si}, \mathrm{Ni}$, $\mathrm{Mo}$ and $\mathrm{Ti}$ at $450{ }^{\circ} \mathrm{C}$ [14]. Moreover, the drive to reduce the interfacial free energy could further promote the segregation of $\mathrm{Mn}$ and phase transformation

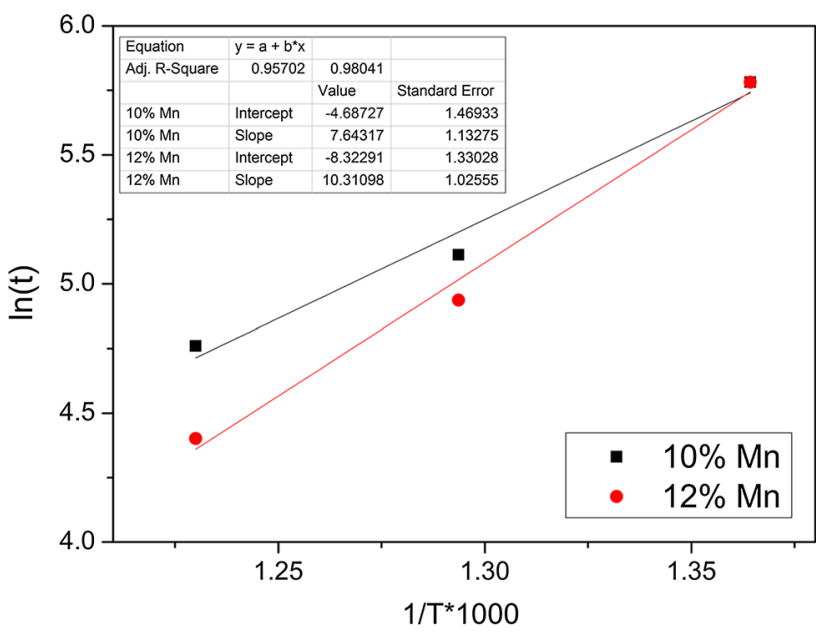

Figure 3 Calculation of the activation energy for austenite formation in the $10 \% \mathrm{Mn}$ and $12 \% \mathrm{Mn}$ alloy. 
at the interface, making local nucleation of reverted austenite much easier. It also explains why the nucleation of reverted austenite at the interface occurred preferentially to that within the martensite laths. Han and Lee [27] also reported that austenite reversion could occur without diffusion when heating rate was faster than $15{ }^{\circ} \mathrm{C} / \mathrm{s}$ which is the case in this study. All the evidence indicates that the initial formation of reverted austenite was highly likely to be a shear-dominated process accompanied by a prior or simultaneous diffusion of a small amount of $\mathrm{Mn}$.

The average size of the reverted austenite formed during this period in the 10 and $12 \%$ Mn alloys was measured from images such as in Figs. 1 and 2. Since a two-dimensional section would not allow the length of the reverted austenite to be determined, only the thickness of reverted austenite was analyzed here. As shown in Fig. 4, there was only limited increase in the lateral dimension of austenite grains with aging time for both alloys at $500{ }^{\circ} \mathrm{C}$, and the average thickness of reverted austenite was approximately constant in the range $100-150 \mathrm{~nm}$. This decelerated kinetics in the lateral growth of austenite grains is attributed to two factors: (i) the austenite growth during this stage depended on the diffusion of $\mathrm{Mn}$ in martensite matrix which is relatively slow at $500{ }^{\circ} \mathrm{C}\left(5.01 \times 10^{-16} \mathrm{~cm}^{2} / \mathrm{s}^{1}\right.$ [28]); (ii) the reverted austenite grains possessed a good resistance to coarsening [29]. Therefore, the higher Mn content of alloy did not lead to an evident difference in the thickness of the reverted austenite.

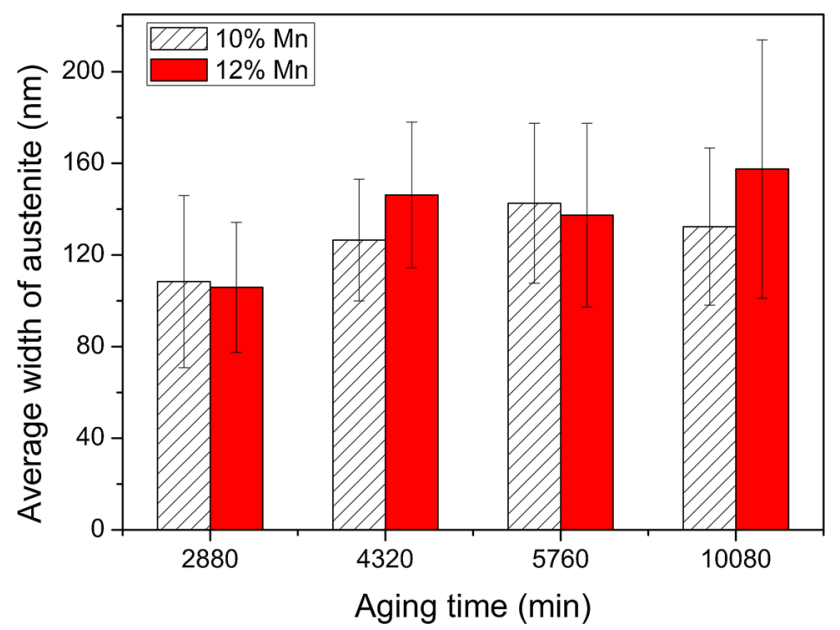

Figure 4 Average thickness of lath-like reverted austenite after aging at $500{ }^{\circ} \mathrm{C}$ for different durations in the $10 \% \mathrm{Mn}$ and $12 \%$ Mn alloys.
The evolution in the thickness of the reverted austenite laths observed in this study agrees with the work of Luo et al. [22], who studied the dimensions of austenite during intercritical annealing of a $5 \mathrm{Mn}$ steel and proposed four stages of size evolution. Using a numerical analysis using the DICTRA software, Luo et al. proposed a very rapid increase in thickness of austenite (from $4 \mathrm{~nm}$ to tens of nanometers within $10^{-3} \mathrm{~s}$ ) in stage I before a pause for $\sim 1 \mathrm{~s}$ (stage II). The whole process is so fast that only the size in stage II is considered as experimentally observable, which agrees with the current observation that nanoscale austenite layers were formed as soon as austenite formation started in $\mathrm{Mn}$ based maraging steel (Figs. $1 \mathrm{~b}$ and $2 \mathrm{a}$ ). In stage III, lateral growth of austenite grains initiates but at a much decreased rate, which is consistent with the period of moderate austenite growth controlled by Mn diffusion observed in this study [for the 10\% Mn alloy, the time up to $5760 \mathrm{~min}$; for the $12 \% \mathrm{Mn}$ alloy, the time up to $4320 \mathrm{~min}$ (Fig. 4)]. In stage IV, the volume fraction and thickness of austenite reach a maximum followed by a small reduction in size (of the order of tens of nanometers). This is proposed to result from the variation of $\mathrm{Mn}$ concentration gradient near the interface in ferrite after the maximum fraction of austenite is achieved [22]. In the current work, a small decrease in the austenite thickness was observed for both alloys at the end of aging (after the maximum fraction of austenite was obtained), as shown in Table 1 and Fig. 4, although this change was within the statistical error.

\section{Conclusions}

Based on the experimental results and discussion presented above, the austenite reversion is briefly divided into two stages:

1. The nucleation of reverted austenite at martensite grain boundaries occurred at the onset of aging followed by the nucleation of austenite within martensite laths. The nucleation process was governed by a shear mechanism assisted by a prior or simultaneous diffusion of a small amount of $\mathrm{Mn}$. Due to the structural disorder at the interface, there is a higher driving force for the segregation of $\mathrm{Mn}$ and phase transformation, which made the rapid nucleation of reverted 
austenite at grain boundaries easier, while the nucleation of reverted austenite within martensite laths was kinetically slower.

2. During the subsequent aging, the accumulated Mn enrichment at newly formed $\alpha^{\prime} / \gamma$ interfaces led to the austenite layers gradually growing to lath-like reverted austenite, which means the lateral growth of reverted austenite in this stage was mainly supported by the diffusion of Mn. As the diffusivity of $\mathrm{Mn}$ in the martensite matrix is relatively low, the diffusion-controlled austenite growth was slow. The resistance to coalescence between adjacent reverted austenite is another reason why reverted austenite could maintain nanoscale dimensions for a long aging time. At the end of austenite formation, a small reduction in austenite thickness was observed for longer aging times.

The present work is undertaken in collaboration with Tata Steel. Qian is grateful to China Scholarship Council (CSC) and Department for Business, Innovation and Skills (BIS) for the award of a Ph.D. scholarship for studying at University of Sheffield.

\section{Compliance with ethical standards}

Conflict of interests The authors declare that they have no known competing financial interests or personal relationships that could have appeared to influence the work reported in this paper.

Open Access This article is distributed under the terms of the Creative Commons Attribution 4.0 International License (http://creativecommons.org/ licenses/by/4.0/), which permits unrestricted use, distribution, and reproduction in any medium, provided you give appropriate credit to the original author(s) and the source, provide a link to the Creative Commons license, and indicate if changes were made.

\section{References}

[1] Raabe D, Ponge D, Dmitrieva O, Sander B (2009) Designing ultrahigh strength steels with good ductility by combining transformation induced plasticity and martensite aging. Adv Eng Mater 11(7):547-555
[2] Raabe D, Ponge D, Dmitrieva O, Sander B (2009) Nanoprecipitate-hardened 1.5 $\mathrm{GPa}$ steels with unexpected high ductility. Scr Mater 60(12):1141-1144

[3] Springer H, Belde M, Raabe D (2013) Bulk combinatorial design of ductile martensitic stainless steels through confined martensite-to-austenite reversion. Mater Sci Eng, A 582:235-244

[4] Qian F, Sharp J, Rainforth WM (2016) Characterisation of L21-ordered Ni2TiAl precipitates in FeMn maraging steels. Mater Charact 118:199-205

[5] Qian F, Sharp J, Rainforth WM (2016) Microstructural evolution of Mn-based maraging steels and their influences on mechanical properties. Mater Sci Eng, A 674:286-298

[6] Viswanathan UK, Dey GK, Sethumadhavan V (2005) Effects of austenite reversion during overageing on the mechanical properties of $18 \mathrm{Ni}$ (350) maraging steel. Mater Sci Eng, A 398(1-2):367-372

[7] Vasudevan VK, Kim SJ, Wayman CM (1990) Precipitation reactions and strengthening behavior in $18 \mathrm{Wt}$ Pct nickel maraging steels. Metall Trans A 21(10):2655-2668

[8] Hochanadel PW, Robino CV, Edwards GR, Cieslak MJ (1994) Heat treatment of investment cast PH 13-8 Mo stainless steel: part I. Mechanical properties and microstructure. Metall Trans A Phys Metall Mater Sci 25A(4):789-798

[9] Cloué JM, Viguier B, Andrieu E (2005) Effect of the metallurgical variables on the yield stress of $\mathrm{PH} 13-08$ steel. Metall Mater Trans A Phys Metall Mater Sci 36(10):2633-2639

[10] Vylezhnev VP, Sukhikh AA, Bragin VG, Kokovyakina SA (1993) Mechanical properties of maraging N18K9M5T steel with residual and reverted austenite. Phys Met Metallogr 75:157-165

[11] Mun S-H, Watanabe M, Williams DB, Li X, Oh KH, Lee $\mathrm{H}-\mathrm{C}$ (2002) Precipitation of austenite particles at grain boundaries during aging of $\mathrm{Fe}-\mathrm{Mn}-\mathrm{Ni}$ steel. Metall Mater Trans A 33(4):1057-1067

[12] Nakagawa H, Miyazaki T, Yokota H (2000) Effects of aging temperature on the microstructure and mechanical properties of $1.8 \mathrm{Cu}-7.3 \mathrm{Ni}-15.9 \mathrm{Cr}-1.2 \mathrm{Mo}-$ low $\mathrm{C}, \mathrm{N}$ martensitic precipitation hardening stainless steel. J Mater Sci 35(9):2245-2253. https://doi.org/10.1023/A:1004778910345

[13] Leitner H, Schober M, Schnitzer R, Zinner S (2011) Strengthening behavior of $\mathrm{Fe}-\mathrm{Cr}-\mathrm{Ni}-\mathrm{Al}-(\mathrm{Ti})$ maraging steels. Mater Sci Eng, A 528(15):5264-5270

[14] Raabe D, Sandlöbes S, Millán J, Ponge D, Assadi H, Herbig M, Choi P-P (2013) Segregation engineering enables nanoscale martensite to austenite phase transformation at grain boundaries: a pathway to ductile martensite. Acta Mater 61(16):6132-6152 
[15] Schumann H (1967) On the causes of the high degree of work-hardening of high-manganese (hadfield) steel. Neue Hütte 12:220-226

[16] Martínez J, Cotes SM, Cabrera AF, Desimoni J, Guillermet $\mathrm{AF}$ (2005) On the relative fraction of $\varepsilon$ martensite in $\gamma-\mathrm{Fe}-$ Mn alloys. Mater Sci Eng, A 408(1-2):26-32

[17] Duchateau D, Guttmann M (1981) An X-ray microanalysis study of the partition of manganese in 6 and $9 \%$ Mn cryogenic steels and its influence on the stability of austenite dispersed in a tempered martensitic matrix. Acta Metall 29(7):1291-1297

[18] Plichata MR, Aaronson HI (1974) Influence of alloying elements upon the morphology of austenite formed from martensite in Fe-C-X alloys. Metall Trans 5(12):2611-2613

[19] Schnitzer R, Radis R, Nöhrer M, Schober M, Hochfellner R, Zinner S, Povoden-Karadeniz E, Kozeschnik E, Leitner H (2010) Reverted austenite in PH 13-8 Mo maraging steels. Mater Chem Phys 122(1):138-145

[20] Sinha PP, Sivakumar D, Babu NS, Tharian KT, Natarajan A (1995) Austenite reversion in $18 \mathrm{Ni} \mathrm{Co-free} \mathrm{maraging} \mathrm{steel.}$ Steel Res 66(11):490-494

[21] Hirano K, Cohen M, Averbach B (1961) Diffusion of nickel into iron. Acta Metall 9(5):440-445

[22] Luo H, Shi J, Wang C, Cao W, Sun X, Dong H (2011) Experimental and numerical analysis on formation of stable austenite during the intercritical annealing of $5 \mathrm{Mn}$ steel. Acta Mater 59(10):4002-4014

[23] Kim S-J, Wayman CM (1990) Precipitation behavior and microstructural changes in maraging $\mathrm{Fe}-\mathrm{Ni}-\mathrm{Mn}-\mathrm{Ti}$ alloys. Mater Sci Eng, A 128(2):217-230

[24] Shiang LT, Wayman CM (1988) Maraging behavior of an $\mathrm{Fe}-19.5 \mathrm{Ni}-5 \mathrm{Mn}$ alloy II: evolution of reverse-transformed austenite during overaging. Metallography 21(4):425-451

[25] Kaluba W, Taillard R, Foct J (1998) The bainitic mechanism of austenite formation during rapid heating. Acta Mater 46(16):5917-5927

[26] Mehrer H (ed) (1990) Diffusion in solid metals and alloys, vol 26. Springer, Berlin

[27] Han J, Lee Y-K (2014) The effects of the heating rate on the reverse transformation mechanism and the phase stability of reverted austenite in medium Mn steels. Acta Mater 67:354-361

[28] Nohara K, Hirano K (1970) Diffusion of manganese into iron. In: Proceedings of the international conference science and technology of iron and steel, p 11

[29] Hara T, Maruyama N, Shinohara Y, Asahi H, Shigesato G, Sugiyama M, Koseki T (2009) Abnormal $\alpha$ to $\gamma$ transformation behavior of steels with a martensite and bainite microstructure at a slow reheating rate. ISIJ Int 49(11):1792-1800 